\title{
Effect of the displacement rate and inclination angle in steel fiber pullout tests
}

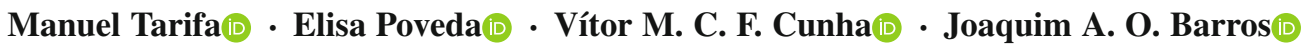

Received: 5 August 2019 / Accepted: 29 October 2019 / Published online: 22 November 2019

(C) Springer Nature B.V. 2019

\begin{abstract}
This paper summarizes the results obtained in an experimental campaign on the effect of the displacement pullout rate and the inclination angle of the steel fiber pullout tests. For that purpose, specimens were obtained from a self-compacting concrete with a compressive strength of $86 \mathrm{MPa}$. In the experimental program, hooked-end steel fibers of $0.75 \mathrm{~mm}$ diameter and $60 \mathrm{~mm}$ length were used. Tests were executed with both hooked-end fibers, and smooth fibers obtained from the former by cutting the hooked end. For both type of fibers, their embedment length into concrete was $20 \mathrm{~mm}$, and the influence of fiber inclination angle toward the load direction was investigated by adopting values of $0^{\circ}, 30^{\circ}$ and $60^{\circ}$. The tests were performed at displacement rates of $0.01,0.1$ and $1 \mathrm{~mm} / \mathrm{s}$. The results have shown that the peak pullout load increased with the inclination angle, in particular for the smooth series. Furthermore, higher displacement rates led to a higher energy absorption capacity for the pullout of the
\end{abstract}

\section{Tarifa $(\bowtie)$}

E.T.S.I. Aeronáutica y del Espacio, Universidad Politécnica de Madrid, Pza. del Cardenal Cisneros 3, 28040 Madrid, Spain

e-mail: manuel.tarifa@upm.es

E. Poveda

E.T.S. de Ingenieros de Caminos, C. y P., UCLM, Avda. Camilo José Cela s/n, 13071 Ciudad Real, Spain

V. M. C .F. Cunha · J. A. O. Barros

ISISE, Institute of Science and Innovation for Bio-Sustainability (IB-S), Department of Civil Engineering, University of Minho, 4800-058 Guimarães, Portugal smooth fibers, while the energy absorption remained almost stable for hooked-end fibers.

Keywords Hooked-end steel fibers · Smooth steel fibers $\cdot$ Concrete $\cdot$ Inclination angle $\cdot$ Displacement pullout rate

\section{Introduction}

Fiber reinforced concrete, FRC, is an heterogeneous material where the fibers are randomly distributed in a concrete matrix. It is shown that the use of fibers increases the energy absorption capacity and the fracture toughness of the composite (Gokoz and Naaman 1981; Banthia and Trottier 1991; Naaman et al. 1991a; Leung and Ybanez 1997; Robins et al. 2002; Laranjeira 2010). These capabilities are even higher for dynamic displacement rates, as accounted by Bindiganavile and Banthia (2005), Kim et al. (2008), Xu et al. (2016), which makes the FRC very attractive for applications such as structures at risk of seismic forces. Recently, construction systems against terrorist attacks are necessary. These systems have to meet with the requirements regarding the structural integrity against impulsive forces and even explosive loads. The use of fibers to reinforce the concrete perfectly complies with this requisite.

In FRC, the fibers are embedded in a cementitious matrix through an interface, so the mechanical behavior of the FRC is mostly influenced by this interface, 
as well as by the fiber's micromechanical mechanisms. Thus, there is a transfer of stresses between the concrete matrix and the fibers whose efficiency depends on the strength of the matrix and the fiber geometry (Banthia and Trottier 1994; Cunha et al. 2010; Abdallah et al. 2016). For this reason, the study of the bond mechanisms between the fibers and the cement matrix is of paramount importance, as well as knowing the parameters affecting its strength. Therefore, it is possible to understand the behavior of the fibers in the FRC through the pullout tests of single fibers as referred by Tai et al. (2016).

The pullout test characterizes the bond properties of the concrete-fiber interface. It consists on the extraction of an embedded single fiber from a concrete matrix. From the tests, mechanical parameters are obtained, i.e. the energy absorbed, as the area under the loadslip curve, or the bond resistance of the concrete-fiber interface (Pompo et al. 1996). Furthermore, the pullout tests are designed to include key parameters that best simulate the real conditions of the fibers inside the concrete matrix. Previous research has shown that the most important key parameters are the material and geometry characteristics of the fiber, its inclination angle regarding the loading direction, the displacement rate at which the fibers are pulled out, $\dot{\delta}$, and the mechanical and chemical characteristics of the concrete matrix.

Regarding the type of fiber, the literature points out that the hooked-end fibers are more widely used in cementitious composites compared with other types of steel fibers (Kim 2009; Baran et al. 2012). These fibers are highly efficient in using their hook to produce a mechanical anchorage in concrete (Banthia and Trottier 1994; Cunha et al. 2008; Kim et al. 2009; Cunha et al. 2010). However, it is also important to know the behavior of the equivalent smooth fiber, since it is governed by a physicochemical bond, i.e. the adhesion and frictional forces, as pointed by Nammur and Naaman (1989), Naaman et al. (1991a,b), Abrishambaf et al. (2017). These fibers are usually employed in high performance concretes, HPC, since the bond capacity of the hooked-end fibers is limited by its rupture (Xu et al. 2016) produced by the high induced fiber tensile stress during pullout because of its mechanical anchorage.

The inclination angle of the fibers is also an important key parameter. In the 90s, Banthia and Trottier (1994) studied the influence of the inclination of deformed steel fibers on their pullout performance. They studied fibers inclined at $0^{\circ}, 15^{\circ}, 30^{\circ}, 45^{\circ}$ and $60^{\circ}$, and they found that the inclined fibers supported smaller peak pullout loads and absorbed less energy than the aligned fibers. They explained that this behavior was favored by the use of a highstrength concrete matrix, which led to brittle failure modes of the fiber and the matrix and decreased the absorbed energy. Nonetheless, several researchers as Robins et al. (2002), Bindiganavile and Banthia (2005), Markovic (2006), Cunha et al. (2010) found an increase in the bond strength for steel and polymeric fibers with small inclination angles. In particular, Robins et al. (2002); Markovic (2006) mentioned that although the strength grows with the inclination angle, there would be an optimum inclination in-between $0^{\circ}$ and $20^{\circ}$. Fiber rupture and matrix spalling are very likely from $30^{\circ}$ onwards, due to the fact that the bending and the frictional stress concentrate at the fibers exit point (Leung and Ybanez 1997; Laranjeira et al. 2010a). Regardless, Laranjeira (2010) pointed out that the friction and spalling influences appear to depend on the strength differential, i.e., when a low-strength matrix was combined with a high tensile strength fiber or vice versa. Xu et al. (2016) studied smooth, twisted, hooked-end and half-hooked-end fibers, obtained by cutting off the first part of the hook, embedded in ultrahigh strength concrete. They observed higher influence of the inclination angle on the half-hooked-end fibers. In particular, the tests were performed at three inclination angles, $0^{\circ}, 20^{\circ}$ and $45^{\circ}$, and two displacement pullout rates, 0.025 and $25 \mathrm{~mm} / \mathrm{s}$, concluding that the $20^{\circ}$ inclination angle was the most rate sensitive. Nonato Da Silva et al. (2019) developed a comprehensive analytical model for the optimization of material and geometry properties of steel fibers considering their inclination regarding the loading direction and the relevant properties of the cementitious surrounding medium.

Most of the research on the behavior of the fiber pullout has been performed at a static rate (Alwan et al. 1999; Abdallah et al. 2016, 2017). In this respect, the study of the effect of the displacement pullout rate on the fiber behavior is not profuse and it has been a controversial topic. In the 80 s and 90 s the research on this topic was scarce (Gokoz and Naaman 1981; Banthia and Trottier 1991). The research on this effect has, however, increased in the last years (Kim et al. 2008; Abu-Lebdeh et al. 2010; Tai et al. 2016; Xu et al. 2016; Tai and El-Tawil 2017; Nieuwoudt and Boshoff 2017; Bhutta et al. 2018). To the best of these authors' 
knowledge, the first research on the fiber displacement pullout rate effect was performed by Gokoz and Naaman (1981). They studied the effect of the dynamic displacement rates on steel, glass and polypropylene smooth fibers, finding not a clear rate effect on any of them. The authors even cited a work by Vos and Reinhardt, who found an insensitive behavior to the displacement rate effect when smooth steel bars are pulled out. Kim et al. (2008, 2009) reached a similar conclusion. They studied hooked-end fibers being pulled out from quasi-static to displacement rates representative of seismic loading conditions, namely, 0.018, $0.18,1.8$ and $18 \mathrm{~mm} / \mathrm{s}$, on concrete matrices of different resistances. They concluded that those fibers were not influenced by the displacement rate in any of the studied matrices. The justification was attributed to the localization of the microcracking in a small region on the vicinity of the hook.

On the other hand, other authors found the opposite behavior. In fact, Banthia and Trottier (1991) tested deformed steel fibers at static and impact loading rates and they found an increase of the peak load with the loading rate. Tai et al. (2016) studied the pullout behavior of short smooth, long smooth, hooked-end and twisted fibers at the same displacement rates than Kim et al. (2008, 2009), namely, from the quasi-static of $0.018 \mathrm{~mm} / \mathrm{s}$, to the seismic ones of $18 \mathrm{~mm} / \mathrm{s}$, as well as impact rates of 180 and $1800 \mathrm{~mm} / \mathrm{s}$. All the fibers they tested have shown a rate dependent behavior, the highest dependency for the long smooth and twisted fibers, and the lowest for the short smooth and hooked-end fibers. Xu et al. (2016) tested smooth, twisted, hookedend and half-hooked-end fibers, obtained by cutting off the first part of the hook, at four different pullout loading rates, ranging from 0.025 to $25 \mathrm{~mm} / \mathrm{s}$. They found that all of them were loading rate dependent with respect to the maximum pullout load, especially the half-hooked-end fibers. They justified this dependency through the sensitivity of the crack formation to the strain rate, i.e. the displacement rate sensitivity is produced by the formation of microsplitting cracks and the damage of cement-based matrix at the fiber tunnel of singly pulled out fibers.

Some researchers found divergent behaviors according to the type of fiber they studied. Abu-Lebdeh et al. (2010) tested deformed and smooth fibers and measured the results in terms of peak load, total pullout work and energy absorption. They found that higher displacement rates increased the peak load of the deformed fibers, while the undeformed remained insensitive. In addition, they pointed out that the fiber failure mode changed with the displacement rate from a complete pullout at a quasi-static rate to fiber rupture under seismic displacement rates. Similarly, Nieuwoudt and Boshoff (2017) investigated the pullout behavior of smooth and hooked-end steel fibers under sustained loads and different loading rates. They concluded that straight steel fibers have shown insignificant rate effect; however, hooked-end steel fibers presented a rate effect, especially in the slip at maximum load. They justified this rate sensitivity through the contribution of the hooked-end, i.e. the displacement rate effect is induced by the visco-elastic behavior of the interface between the hook and the matrix. Tai and El-Tawil (2017) found an unlikely behavior of the fibers they tested. They performed a detailed study of steel fibers of several shapes, fibers at different orientation toward the loading direction, and using the displacement rates adopted by Kim et al. $(2008,2009)$, i.e. a range from a quasi-static of $0.018 \mathrm{~mm} / \mathrm{s}$ to a dynamic one of $1800 \mathrm{~mm} / \mathrm{s}$. They concluded that smooth fibers presented an increasing influence with the loading rate, while hooked-end fibers were less sensitive to the loading rate and produced more matrix damage and spalling, especially with the increase of the inclination angle and the loading rate.

Therefore, this research aims to contribute more results from reliable pullout tests. The key novelty is to disclose the rate-dependent mechanisms involving the pullout process. Thereby, the fibers were extracted at different pullout displacement rates, from the quasistatic one of $0.01 \mathrm{~mm} / \mathrm{s}$, to the dynamic ones of 0.1 and $1 \mathrm{~mm} / \mathrm{s}$. Furthermore, the tests were performed on smooth and hooked-end steel fibers, combining three fiber inclination angles of $0^{\circ}, 30^{\circ}$ and $60^{\circ}$. This set of parameters allow to derive important conclusions on the influence of fiber aspects that condition its reinforcement effectiveness (geometry, anchorage mechanisms, orientation) when fibers are pulled out at a displacement rate covering possible real scenarios of SFRC applications.

Hereinafter, the paper is structured as follows: the experimental procedure is presented in the next Section, which is followed by the description of the results of the tests and the discussion. Finally, the conclusions are drawn in the last Section. 
Table 1 Quantity and mix proportion in weight of the SCC

\begin{tabular}{lll}
\hline Component & Quantity $\left(\mathrm{kg} / \mathrm{m}^{3}\right)$ & Proportion \\
\hline Cement & 389.4 & 1 \\
Filler & 267.2 & 0.69 \\
Sand & 847.6 & 2.18 \\
Coarse aggregate & 739.4 & 1.67 \\
Water & 64.7 & 0.17 \\
Superplasticizer & 6.8 & 0.017 \\
\hline
\end{tabular}

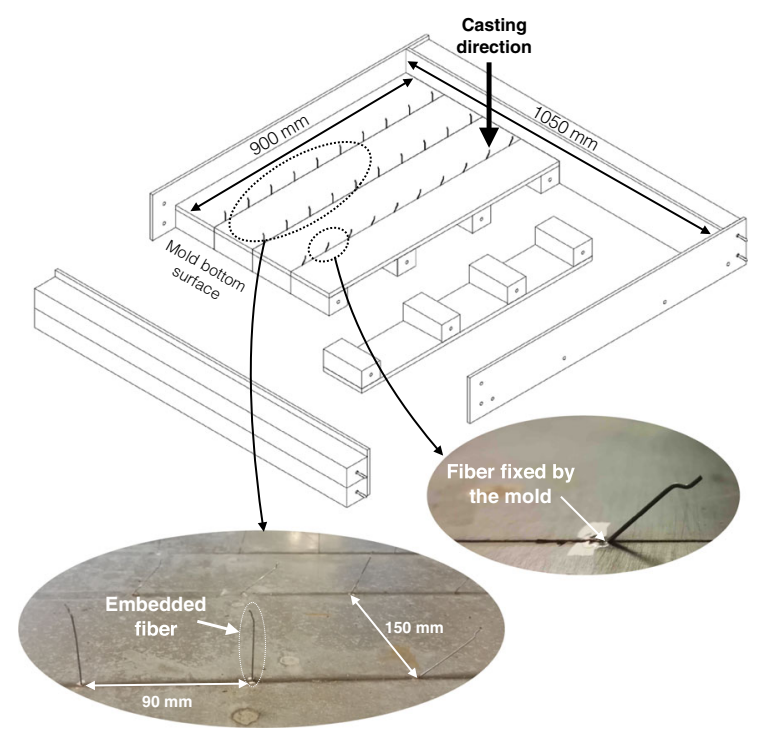

Fig. 1 Mold sketch with the positioning of the fibers and the concrete casting direction

\section{Experimental procedure}

In this section, the materials, specimens and test procedure employed in the research are described.

\subsection{Materials and specimens}

For a single batch of self-compacting concrete, SCC, a concrete slab of $1050 \times 900 \times 60 \mathrm{~mm}^{3}$, Fig. 1 where the fibers will be disposed for the pullout tests, and three $150 \mathrm{~mm}$ edge length cubic specimens for the assessment of the SCC compressive strength, were produced. The concrete matrix was made of a granite coarse aggregate with a maximum size of $20 \mathrm{~mm}$, cement CEM I 42.5 R, limestone filler and superplasticizer. The water cement ratio, w/c, was 0.17 . The mix proportion by weight of the concrete matrix is shown in Table 1.

In order to determine the self-compacting properties of the concrete, the slump flow test was performed according to EN 12350-8 (2010) standard. The value of the $T_{500}$ was 4.3 seconds and the spread diameter of the concrete reached $77 \mathrm{~cm}$ when it was allowed to flow freely. After 30 days, the compressive strength of the concrete was measured by testing the three cubes, getting a value of $86 \mathrm{MPa}$ and a variation coefficient of $1.2 \%$.

Hooked-end steel fibers of $0.75 \mathrm{~mm}$ diameter and $60 \mathrm{~mm}$ length were used. Smooth fibers were also employed, obtaining them by cutting the hook of the hooked-end, resulting a fiber with a length of $55 \mathrm{~mm}$. The tensile tests on the steel of the fibers were performed by Cunha et al. (2010). They obtained a tensile strength of $1313 \mathrm{MPa}$.

Several individual steel fibers were placed in the concrete slab with a prescribed inclination angle and an embedded length of $20 \mathrm{~mm}$. The minimum distance between the fibers was $90 \mathrm{~mm}$. An special mold, made of waterproof wood and fully detachable, was designed in order to allow the positioning and fixation of the fibers with care, see Fig. 1. The fibers were placed in the mold one by one to fully ensure their embedment depth and inclination angle. Then, the slab was cast, covered with a plastic and cured for 3 days in the laboratory environment, at approximately $26^{\circ} \mathrm{C}$. After that, the slab was de-molded and stored in the laboratory. The fibers were perfectly embedded in the concrete matrix without damage, they were $90 \mathrm{~mm}$ far from the neighbor fibers of the same row and $150 \mathrm{~mm}$ to the fibers in adjacent rows, see Fig. 1. Later, the slab was cut following the fiber rows in 10 strips of $900 \mathrm{~mm}$ length and $150 \mathrm{~mm}$ width, which contained 10 fibers each.

A total of 60 fibers were embedded in the slab, although only 54 were tested, of which 24 were smooth fibers and 30 were hooked-end fibers. Thereby, around 10 fibers were positioned for each inclination angle, from aligned, $0^{\circ}$, to inclined fibers at $30^{\circ}$ and $60^{\circ}$.

\subsection{Pullout test set-up}

The single pullout tests were carried out at the Laboratory of the Structural Division, LEST, University of Minho, Azurém Campus, Guimarães (Portugal). For 


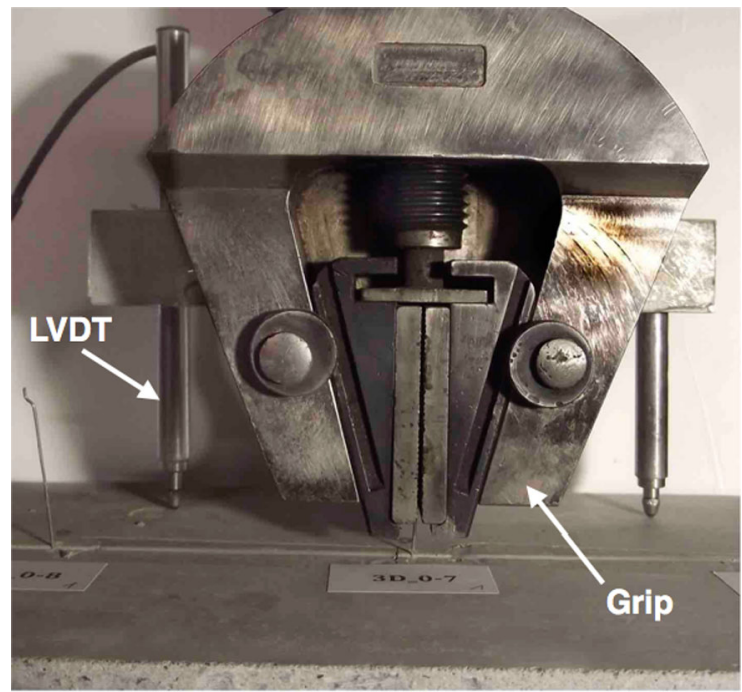

Fig. 2 Pullout test configuration

this, an hydraulic actuator of $50 \mathrm{kN}$ of loading capacity and $200 \mathrm{~mm}$ of maximum displacement was employed. The actuator was equipped with an AEP-Transducers load cell with a resolution of $0.05 \%$ and $50 \mathrm{kN}$ of loading capacity. A specimen containing 10 embedded fibers each was placed and fixed to a stiff steel frame under the actuator. Prior to the test of each fiber, the specimen was carefully centered under the actuator and then fixed to the steel frame. A steel grip was attached to the actuator, to firmly fasten the fibers without slip between the fiber and the grip, Cunha et al. (2010), Fig. 2. For the measurement of the fiber pullout slip, two displacement sensors, Linear Variable Differential Transducers-LVDT-(linear stroke $\pm 10 \mathrm{~mm}$ ), were attached to the grip, see Fig. 2. The same setup pullout configuration was employed by Abrishambaf et al. (2017). They deeply described the clamping device, they evaluated the fiber slippage at the grip by means of a microscope camera, and found it negligible.

A total of 18 parameter configurations were tested. In fact, the inclination angles of smooth and hookedend fibers, $0^{\circ}, 30^{\circ}$ and $60^{\circ}$ were combined with the displacement pullout rate, ranging from a quasi-static rate of $0.01 \mathrm{~mm} / \mathrm{s}$ to dynamic rates of 0.1 and $1 \mathrm{~mm} / \mathrm{s}$.

It is important to underline that the experimental tests of hooked-end and smooth fibers, regardless of their inclination angle, were loaded perpendicular to the concrete surface, as seen in Fig. 3.

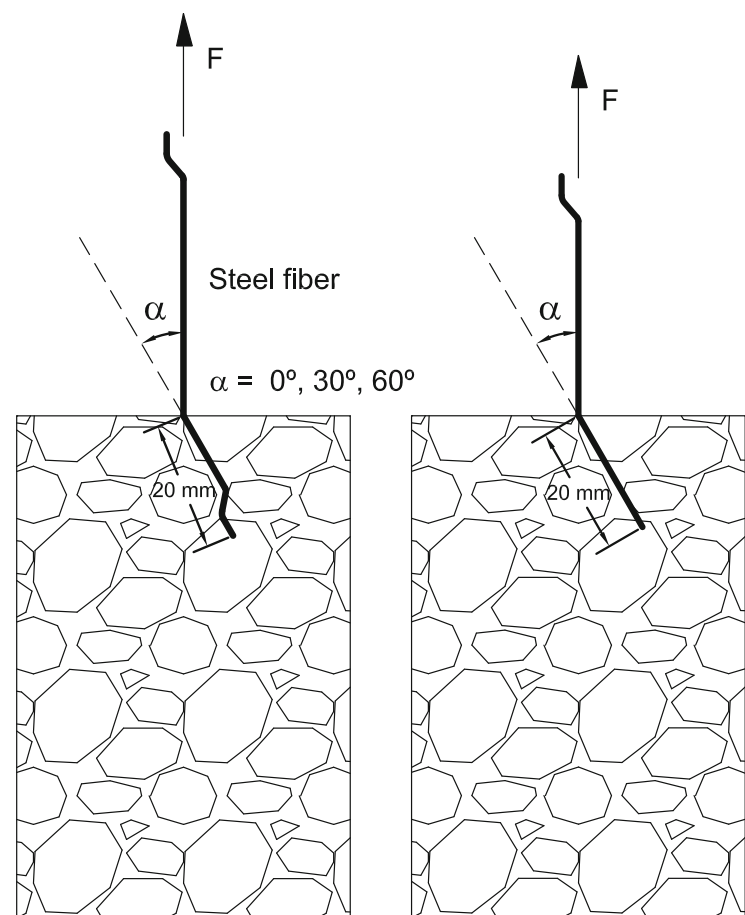

Concrete matrix

(a) Hooked-end fiber (b) Smooth fiber
Fig. 3 Loading direction for embedded a hooked-end and b smooth fibers

\section{Results and discussion}

In this section, the results of the experimental tests are presented and analyzed, and the influence of each variable on the pullout response is thoroughly discussed.

\subsection{Experimental results}

Figure 4 shows five pullout force vs. slip curves for the specific experimental set-up of hooked-end fibers, aligned and with a displacement pullout rate of $1 \mathrm{~mm} / \mathrm{s}$. Slip is the average displacement recorded by the two LVDTs attached to the steel grip, Fig.2, therefore represents the loaded end slip of the fiber (sliding of the fiber in the grip was assured do not has occurred, as Abrishambaf et al. (2017) checked for the same setup configuration; elastic deformation of the protruding part of the fiber is negligible).

Not all the fibers were fully pulled out from the concrete matrix, some of them broke during the pullout process. Table 2 summarizes the number of broken fibers, 


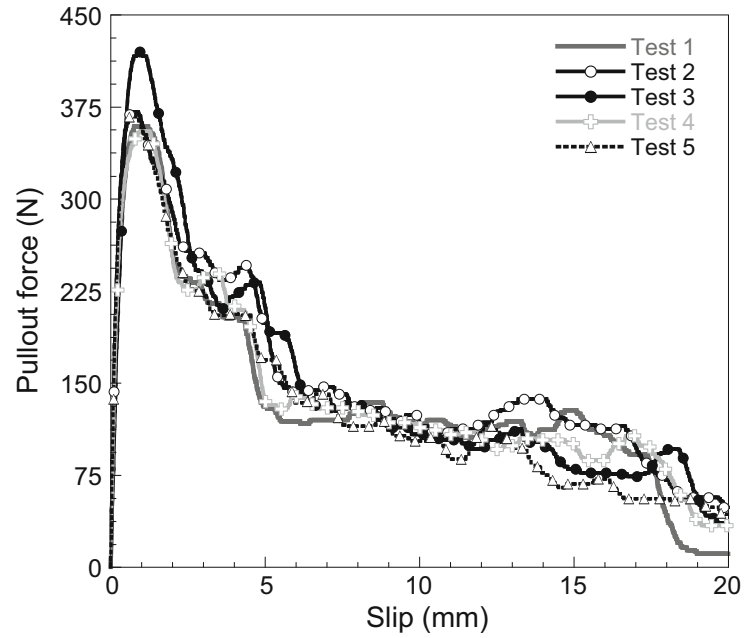

Fig. 4 Pullout tests of hooked-end fibers, aligned $\left(0^{\circ}\right)$, displacement rate $1 \mathrm{~mm} / \mathrm{s}$

in brackets, over the total of fibers tested for each experimental set-up. As can be seen, no smooth fibers broke during the pullout. On the other hand, the hooked-end fibers began to break at an inclination angle of $30^{\circ}$, while all the fibers inclined at $60^{\circ}$ ruptured.

\subsubsection{Effect of the fiber type}

As accounted by several authors like Nammur and Naaman (1989), Naaman et al. (1991a), Abrishambaf et al. (2017), the behavior of the smooth fibers is governed by a physicochemical bond, i.e. the adhesion and frictional forces. The adhesion depends on the properties of the interfacial transition zone, ITZ, and the second depends on both properties of the fiber surface and concrete matrix (Cunha et al. 2010). Thus, Fig. 5a schematically represents the typical behavior of the smooth fibers, where the load increases in a first phase without

Table 2 Fibers tested by experimental set-up, and fibers broken in brackets

\begin{tabular}{llllllll}
\hline$\dot{\delta}(\mathrm{mm} / \mathrm{s})$ & \multicolumn{3}{l}{ Smooth fibers } & & \multicolumn{3}{c}{ Hooked-end fibers } \\
\cline { 2 - 3 } \cline { 7 - 8 } & $0^{\circ}$ & $30^{\circ}$ & $60^{\circ}$ & & $0^{\circ}$ & $30^{\circ}$ & $60^{\circ}$ \\
\hline $0.01^{*}$ & $2(0)$ & $2(0)$ & $3(0)$ & & $6(0)$ & $6(4)$ & $6(6)$ \\
0.1 & $4(0)$ & $4(0)$ & $5(0)$ & & $5(0)$ & $5(1)$ & $5(5)$ \\
1 & $4(0)$ & $4(0)$ & $5(0)$ & $5(0)$ & $5(2)$ & $5(5)$
\end{tabular}

* The results in Table 2, corresponding to the quasi-static displacement pullout rate $(\dot{\delta})$ of $0.01 \mathrm{~mm} / \mathrm{s}$, were obtained by Cunha et al. (2010)

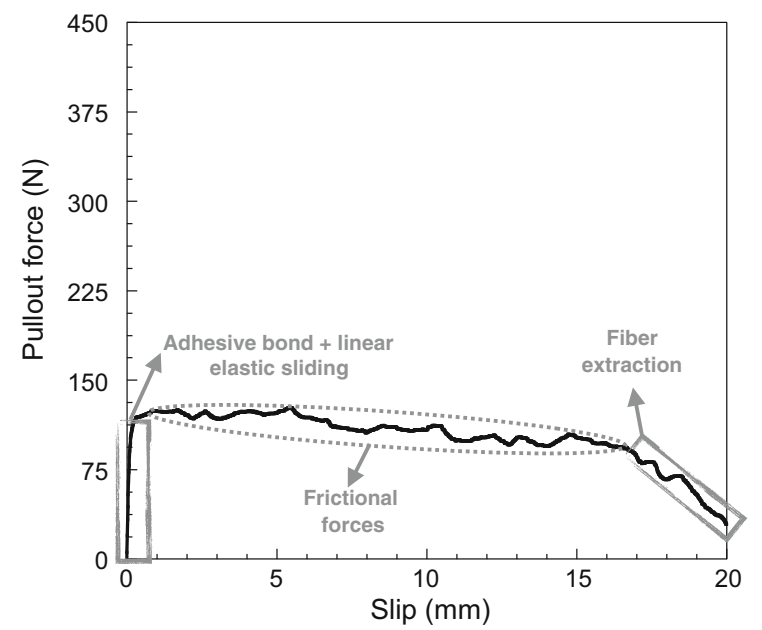

(a) Smooth fiber, angle $0^{\circ}$

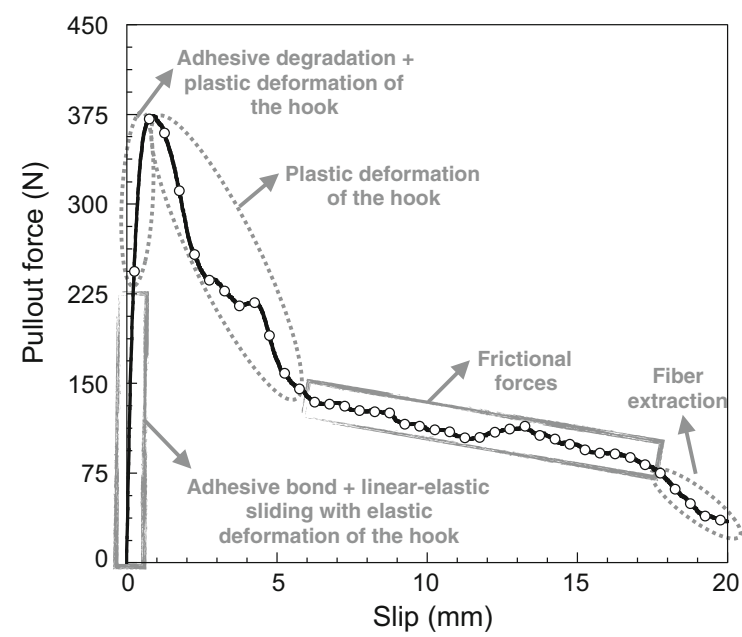

(b) Hooked-end fiber, angle $0^{\circ}$

Fig. 5 Pullout behavior of the a smooth and $\mathbf{b}$ hooked-end fibers

sliding, to continue with a linear-elastic sliding until a first peak when the adhesive bond is exhausted. Then the curve straightens and progressively decreases due to the appearance of the frictional forces. Finally the rapid drop of the load towards the end is due to the small portion of the fiber that remains inside the concrete matrix and the smoothing of the concrete channel until its overall extraction.

On the other hand, hooked-end fibers attach the mechanical contribution of the hook to the physicochemical mechanisms of the fiber-matrix bond. Cunha et al. (2010), Abrishambaf et al. (2017), Nonato Da Silva et al. (2019) described the pullout load versus slip curves of the hooked-end fibers, whose schematic 
explanation is represented in Fig. 5b. Thus, the curve is composed of a straight stage with an adhesive dominant phase with non-slippage, followed by a linear elastic load-slip phase where the hook is elastically deformed, then a non-linear branch associated with the degradation of the adhesive fiber-matrix force, as well as the beginning of the plastic deformation of the hook until the peak load is reached. After that, the peak load is followed by a softening branch when the mechanical anchorage is completely mobilized. Then a straight part begins due to the fiber-concrete friction, with a descendent tendency due to the reduction of the embedded length of the fiber and the smoothing of the concrete channel, up to the overall extraction of the fiber.

The average curves and the scatter, represented by an envelope, were calculated. Thus, Fig. 6 shows the pullout force vs. slip of the nine test set-up combinations for the fiber inclination angles and displacement

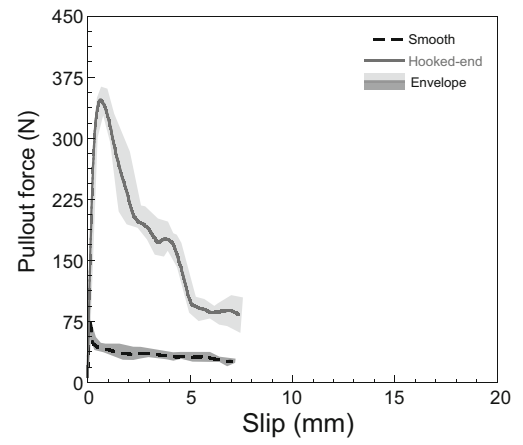

(a) Angle $0^{\circ}$, rate $0.01 \mathrm{~mm} / \mathrm{s}$

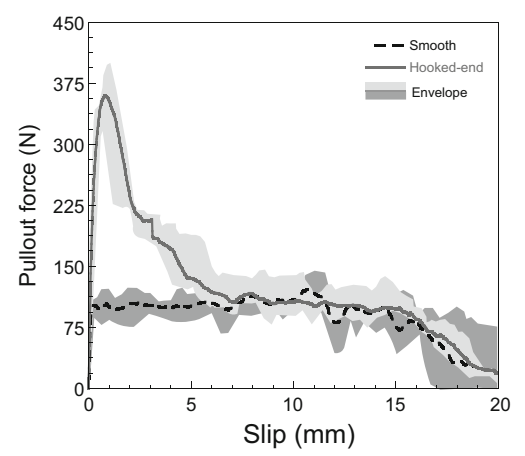

(d) Angle $0^{\circ}$, rate $0.1 \mathrm{~mm} / \mathrm{s}$

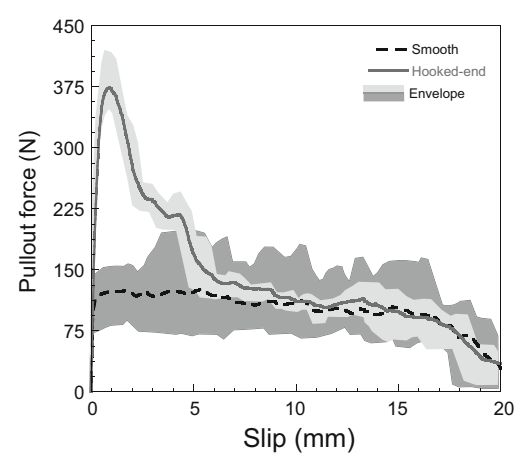

(g) Angle $0^{\circ}$, rate $1 \mathrm{~mm} / \mathrm{s}$

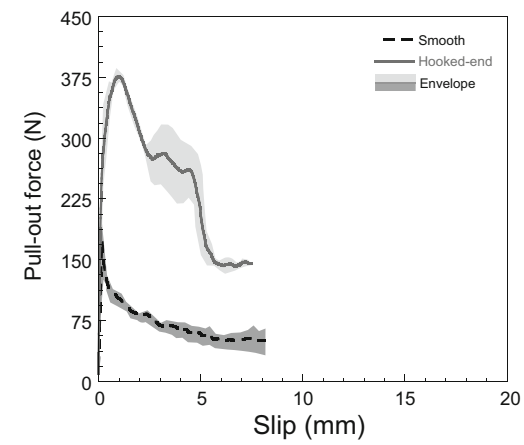

(b) Angle $30^{\circ}$, rate $0.01 \mathrm{~mm} / \mathrm{s}$

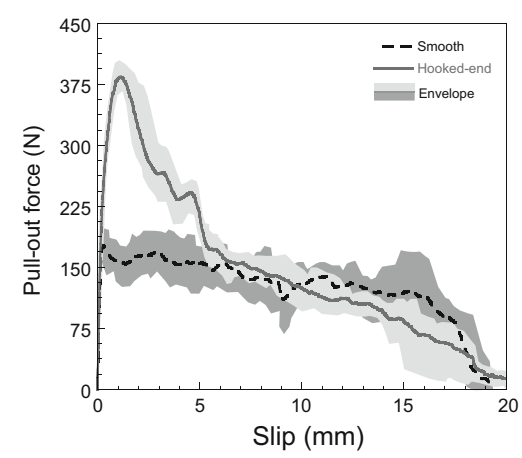

(e) Angle $30^{\circ}$, rate $0.1 \mathrm{~mm} / \mathrm{s}$

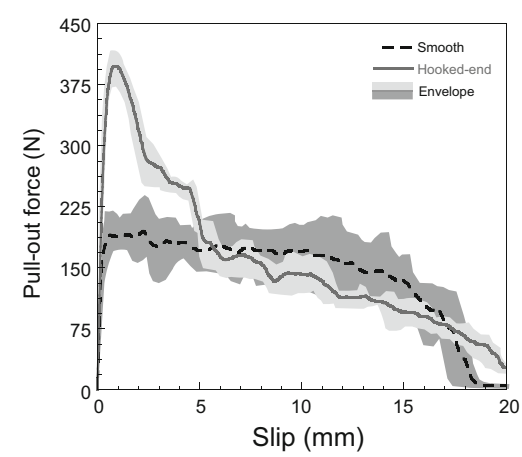

(h) Angle $30^{\circ}$, rate $1 \mathrm{~mm} / \mathrm{s}$

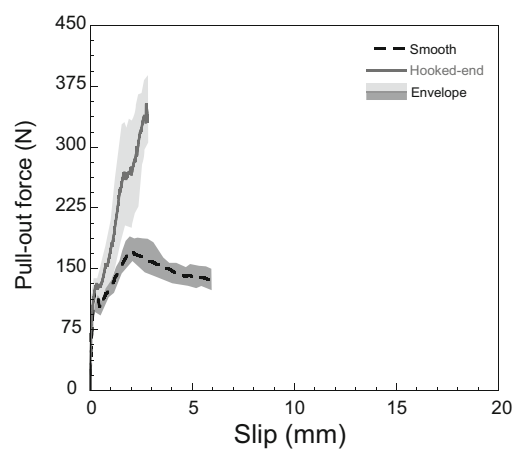

(c) Angle $60^{\circ}$, rate $0.01 \mathrm{~mm} / \mathrm{s}$

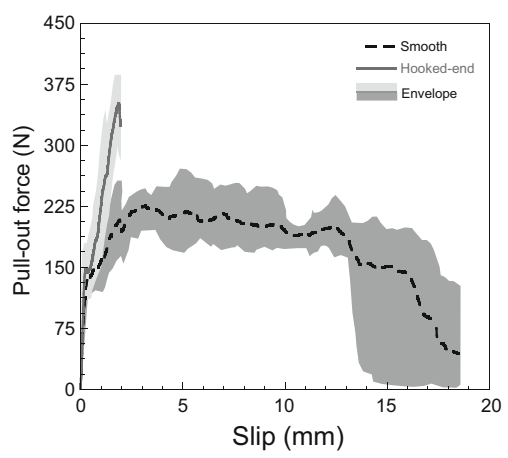

(f) Angle $60^{\circ}$, rate $0.1 \mathrm{~mm} / \mathrm{s}$

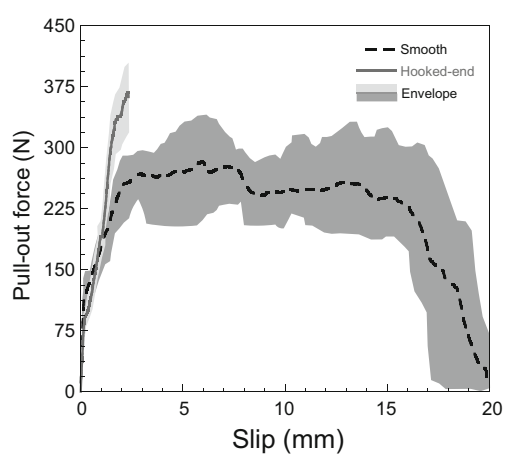

(i) Angle $60^{\circ}$, rate $1 \mathrm{~mm} / \mathrm{s}$

Fig. 6 Envelope and average curves by type of fiber 
pullout rates of both smooth and hooked-end fibers. In particular, Fig. 6 represents the direct comparison of the smooth and hooked-end fibers. Thereby, the dashed curves depicted in this figure represent the mean values of the smooth fiber test series, which shape agrees with the curve described in Fig. 5a. However, the trend is different at the quasi-static rate of $0.01 \mathrm{~mm} / \mathrm{s}$, see Fig. 6a-c, due to the fact that the viscous-elastic/plastic nature of the ITZ makes the smooth fibers rate sensitive. The mean values of the hooked-end fiber test series are also represented in Fig. 6, in solid lines. The shape of these curves coincides with the one described in Fig. 5b. Note that the plastic deformation of the hook phase always ends at around a slip of $5 \mathrm{~mm}$, which is precisely the length of the hook. As the resistance mechanisms described above and represented in Fig. 5 differ, the results between the two types of fibers are different too. At a first sight, the peak loads needed to extract the hooked-end fibers are always higher than the ones for the smooth fibers. However, a deeper analysis of the curves in Fig. 6 shows differences as the inclination angle of the fibers and the displacement pullout rate grow. So, the increase of the displacement rate produces the approach of the post-peak load of the smooth curve to the hooked-end one, Fig. 6a, d, g, which is more pronounced for inclined fibers, even producing that the post-peak load of the smooth fiber to overcome the one of the hooked-end one, as seen when comparing Fig. 6d, e, as well Fig. 6g, h. This phenomenon can be justified by the final shape adopted by the hooked-end fiber, i.e. the straighten hook slips along the final stretch of the concrete channel with a threepoint contact mechanism, as explained by Laranjeira et al. (2010b), and consequently the frictional forces decrease rapidly. On the other hand, the smooth fiber slips with a whole fiber-concrete contact, hence the frictional forces decrease slowly. This observation was corroborated by Poveda et al. (2019), who developed a numerical model aimed to simulate the effects observed in inclined smooth and hooked-end fibers pulled out at different displacement rates. In their study, they compared a pulled out hooked-end fiber with one obtained by the numerical model and they observed the threepoint contact mechanism of the hooked-end fiber.

Note that the comparison of the smooth fibers inclined at $60^{\circ}$ with the hooked-end ones with the same angle is not possible as all these latter series broke before being extracted. In any case, all the peak loads reached by the hooked-end fibers before their rupture

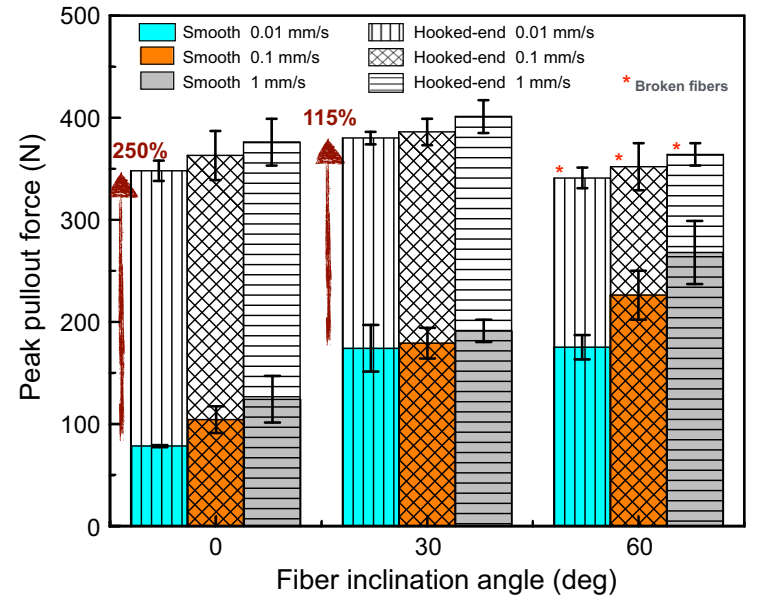

Fig. 7 First peak pullout load by fiber test series

far exceeded the peak load of the smooth fibers, see the solid curves of Fig. 6c, f, i. Furthermore, as some of the hooked-end fibers inclined at $30^{\circ}$ broke, as reported in Table 2, the average curves in Fig. 6b, e, h were calculated excluding those fibers.

Figure 7 compares the smooth and hooked-end fibers, in terms of the first peak load and including error bars representing the scatter, for all the tested series. The plot confirms that the peak load reached by the hooked-end fibers is higher than for smooth fibers. In general, the hooked-end fibers increased the peak load $250 \%$ for an inclination angle of $0^{\circ}$, and $115 \%$ for an inclination of $30^{\circ}$. This differential increase is a consequence of the fact that the inclination angle of $30^{\circ}$ increases more the peak load of smooth fibers than that one of hooked-end fibers. So, the effect of the type of fiber is remarkable in aligned fibers, while for inclined fibers the effect of the hook is not so preponderant. Nevertheless the effect of the inclination angle is discussed in-depth in Sect. 3.1.2.

\subsubsection{Effect of the fiber inclination angle}

The effect of the inclination angle on the pullout response has been previously studied. Although it is generally accepted that the inclination angle enhances the peak pullout force of steel and polymeric fibers (Robins et al. 2002; Bindiganavile and Banthia 2005; Markovic 2006; Cunha et al. 2010), some researchers, as Banthia and Trottier (1994), found the opposite in the 90 s. 
Figure 8 plots the curves, grouped by inclination angles, i.e. each plot represents a series of tests performed for one type of fiber at a determined displacement pullout rate and collecting the three inclination angles, $0^{\circ}, 30^{\circ}$ and $60^{\circ}$. Note that, as some of the hooked-end fibers inclined at $30^{\circ}$ have broken, they were excluded for the calculation of the average curves in Fig. 8d-f. In terms of the first peak load, the plots show that the inclination angle of the fibers usually increased the peak pullout load, but not in the same extent. Thus, the effect of the inclination angle is remarkable for smooth fibers, see Fig. 8a-c. With respect to the aligned fibers, $0^{\circ}$, the peak load increased $123 \%$ (from 78 to $174 \mathrm{~N}$ ) at a displacement rate of $0.01 \mathrm{~mm} / \mathrm{s}$ for the two inclination angles, i.e. $30^{\circ}$ and $60^{\circ}$. However, the $60^{\circ}$ series showed a significant change of the slope in the pre-peak branch, see Fig. 8a, due to the fact that higher stresses appear at the concrete bulk around the fiber's exit zone. Consequently, spalling of the matrix at the exit point of the fiber occurs during the loading branch, and thereafter the peak load is reached at a considerably higher slip. Note that this slip is produced by a combination of the fiber realignment produced by the spalling and the relative displacement between the fiber and the concrete. At a displacement rate of $0.1 \mathrm{~mm} / \mathrm{s}$, the peak load increased $72 \%$ (from 104 to $179 \mathrm{~N}$ ) and $117 \%$ (from 104 to $226 \mathrm{~N}$ ) for an angle of $30^{\circ}$ and $60^{\circ}$, respectively, Fig. $8 \mathrm{~b}$. Finally, at a displacement rate of $1 \mathrm{~mm} / \mathrm{s}$, Fig. 8c, the peak load increased 54\% (from 124 to $191 \mathrm{~N}$ ) in fibers inclined at $30^{\circ}$, and $116 \%$ (from 124 to $268 \mathrm{~N}$ ) for an inclination of $60^{\circ}$.

On the other hand, the behavior of the hookedend fibers, Fig. 8d-f, was completely different from the smooth fibers. Firstly, all the fibers inclined at $60^{\circ}$ have broken before being extracted due to the bending and the frictional stress concentrate at the fibers exit point (Leung and Ybanez 1997; Laranjeira et al. 2010a). The same happened for some of the fibers inclined at $30^{\circ}$, see Table 2 . Note that the average curves in Fig. 8d-f excluded broken fibers inclined at $30^{\circ}$. This observation agrees with Robins et al. (2002), who indicated that the ideal inclination angle to increase the anchorage of the fiber without breakage would be under $20^{\circ}$. Regarding the peak load, the behavior of the non-broken fibers inclined at $30^{\circ}$ increased between 6 and $9 \%$ for the three displacement rates, i.e. $0.01,0.1$ and $1 \mathrm{~mm} / \mathrm{s}$. Note that even the slip at the peak load grew with the inclination angle because of the spalling of the matrix, Fig. 8. This event happened especially in smooth and hooked-end fibers inclined at $60^{\circ}$, although it was also detected for an inclination angle of $30^{\circ}$.

Therefore, the smooth fibers turned out to be more sensitive to the inclination angle than the hooked-end fibers. So, the anchorage provided by the hook of the hooked-end fibers, which dominates over the physicochemical bond, seems that it attenuated the effect of the inclination angle of the fibers. This tendency is clearly represented in Fig. 7, where the growth of the smooth fibers, represented by color filled columns, is more pronounced than the one of the hooked-end fibers, represented by plot filled columns.

A special mention must be done to the surface damage of the concrete after the pullout of the fibers. Robins et al. (2002), Laranjeira (2010), Laranjeira et al. (2010a,b), Cunha et al. (2010), Tai and ElTawil (2017), pointed out that inclined fibers produced spalling in the concrete matrix due to the pressure they exerted at the exit point. Figure 9 show the increasing volume concrete spalling by inclination angle. Thus, the fibers inclined at $60^{\circ}$ produced the largest spalling of the concrete matrix, which experimentally resulted in a higher slip at the peak load and the post-peak, see Fig. 8. For the naked eye, and for the same inclination angle, the concrete spalled during the pullout of the smooth fibers, Fig. 9a, and looks similar to one of the hooked-end fibers, Fig. 9b.

\subsubsection{Effect of the displacement pullout rate}

Although some allusions to the displacement pullout rate effect on the fiber pullout behavior have already been done, in this section this effect is deeply discussed.

In the available bibliography, the effect of the displacement pullout rate on the fiber behavior has been a controversial topic, as deeply introduced in Sect. 1. Thereby some authors did not find any clear effect of the loading pullout rate in their experiments (Gokoz and Naaman 1981; Kim et al. 2008, 2009), while others found it (Banthia and Trottier 1991; Tai et al. 2016; $\mathrm{Xu}$ et al. 2016). Some others found divergent behaviors according to the type of fiber they studied (Abu-Lebdeh et al. 2010; Nieuwoudt and Boshoff 2017).

Figure 10 depicts the average curves of the tested fibers, grouped by displacement pullout velocities, i.e. each plot represents the series of tests performed for one type of fiber, at a determined inclination angle and collecting the three displacement pullout rates employed. 


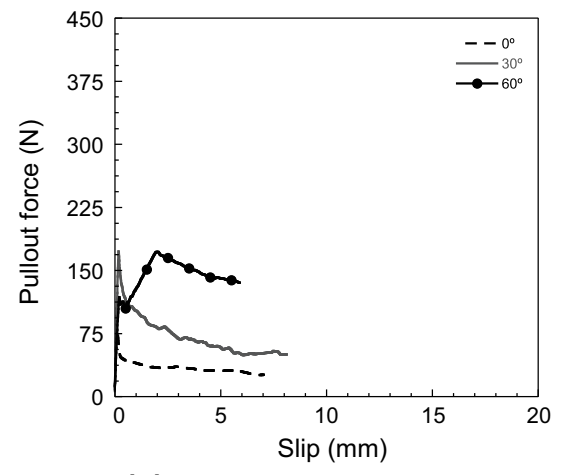

(a) Smooth fibers, rate $0.01 \mathrm{~mm} / \mathrm{s}$

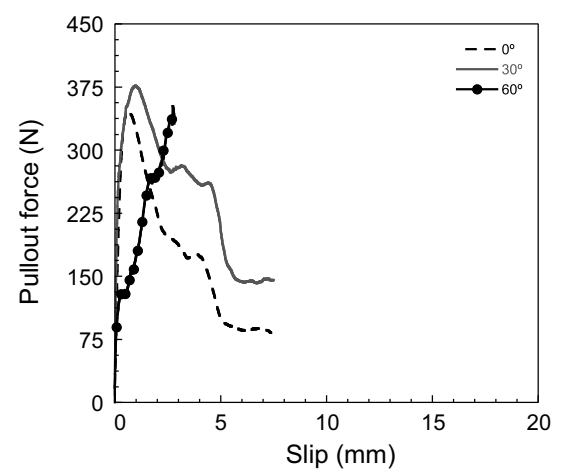

(d) Hooked-end fibers, rate $0.01 \mathrm{~mm} / \mathrm{s}$

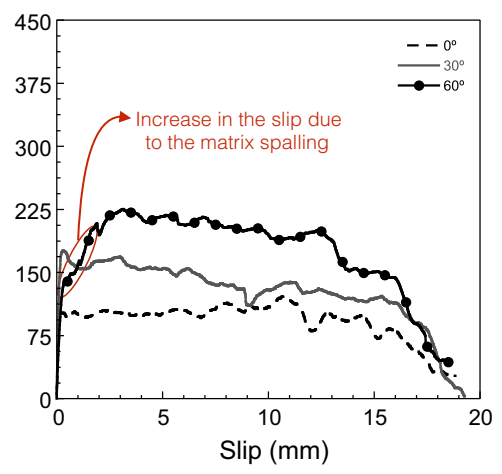

(b) Smooth fibers, rate $0.1 \mathrm{~mm} / \mathrm{s}$

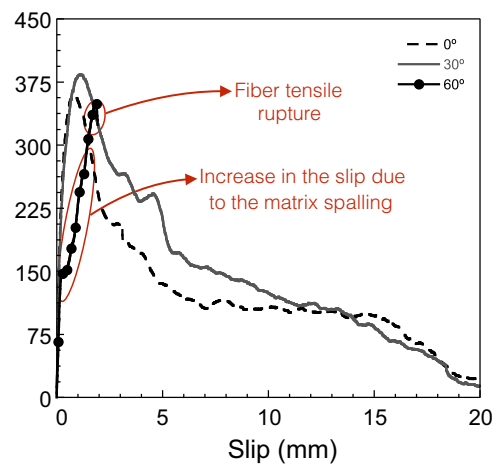

(e) Hooked-end fibers, rate $0.1 \mathrm{~mm} / \mathrm{s}$

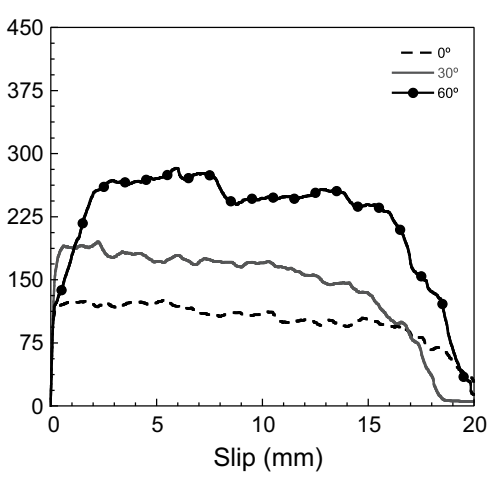

(c) Smooth fibers, rate $1 \mathrm{~mm} / \mathrm{s}$

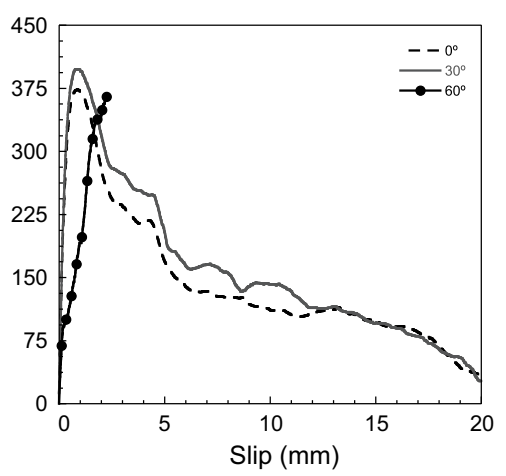

(f) Hooked-end fibers, rate $1 \mathrm{~mm} / \mathrm{s}$

Fig. 8 Average curves for smooth and hooked-end fibers by inclination angle

A quick look of this figure reveals that there is an evident displacement pullout rate dependency of the smooth fibers, while the hooked-end fibers could be considered almost insensitive. These observations are in line with the recent research of Tai et al. (2016), Tai and El-Tawil (2017).

The analysis of the phenomenon in the smooth fibers, in terms of the first peak load and taking the quasi-static displacement rate of $0.01 \mathrm{~mm} / \mathrm{s}$ as a reference, show that for aligned fibers, $0^{\circ}$, the peak load increased 33\% (from 78 to $104 \mathrm{~N}$ ) and 59\% (from 78 to $124 \mathrm{~N}$ ) for the seismic rates of 0.1 and $1 \mathrm{~mm} / \mathrm{s}$, respectively. For the case of smooth fibers inclined at $30^{\circ}$, the peak load increased $10 \%$ (from 174 to $191 \mathrm{~N}$ ) for the displacement rate of $1 \mathrm{~mm} / \mathrm{s}$. Finally, the peak load of the fibers inclined at $60^{\circ}$ increased $29 \%$ (from 175 to $226 \mathrm{~N}$ ) for the rate of $0.1 \mathrm{~mm} / \mathrm{s}$ and $53 \%$ (from 175 to $268 \mathrm{~N}$ ) for the rate of $1 \mathrm{~mm} / \mathrm{s}$. On the other hand, the same analysis for the hooked-end fibers shows a total peak load increase, from the quasi-static displacement rate of $0.01 \mathrm{~mm} / \mathrm{s}$ to the seismic one of $1 \mathrm{~mm} / \mathrm{s}$, of $8 \%$ (from 348 to $376 \mathrm{~N}$ ) for aligned fibers, and 5\% (from 380 to $401 \mathrm{~N}$ ) for fibers inclined at $30^{\circ}$. The hookedend fibers inclined at $60^{\circ}$ were not analyzed due to their rupture.

The proximity of the peak loads observed in Fig. 10, revealed by the analysis just done, and the shape of the complete curves in the same figure, lead us to analyze the phenomenon in terms of the energy absorption during the pullout tests. Thus, the energy absorption has been calculated as the area under the pullout force $v s$. slip, until a fiber slip of $8 \mathrm{~mm}$, as the tests at a rate of $0.01 \mathrm{~mm} / \mathrm{s}$ were performed by Cunha et al. (2010) until this value, see Table 3 .

For a better understanding, the results in Table 3 are plotted in Fig. 11. A quantitative analysis of Table 3 and Fig. 11 show that, in the case of smooth fibers inclined at $0^{\circ}$ and taking the quasi-static displacement rate of $0.01 \mathrm{~mm} / \mathrm{s}$ as a reference, the energy absorption increased $240 \%$ at a rate of $0.1 \mathrm{~mm} / \mathrm{s}$, and $294 \%$ at a 

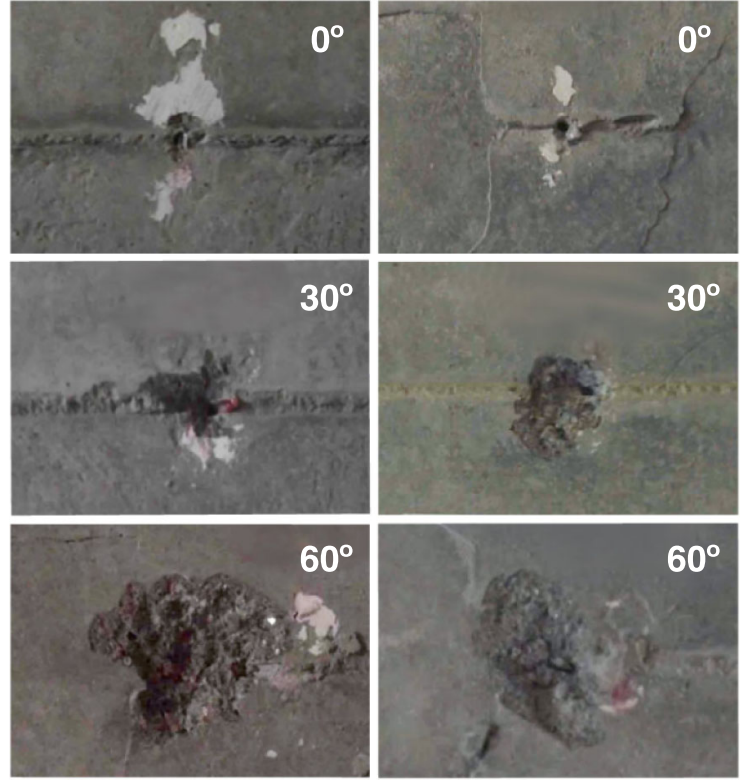

(a) Smooth fibers

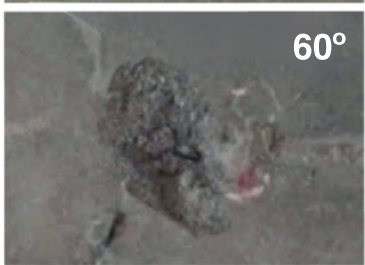

(b) Hooked-end fibers

Fig. 9 Concrete surface after the pullout at a rate of $0.1 \mathrm{~mm} / \mathrm{s}$ of $\mathbf{a}$ smooth and $\mathbf{b}$ hooked-end fibers

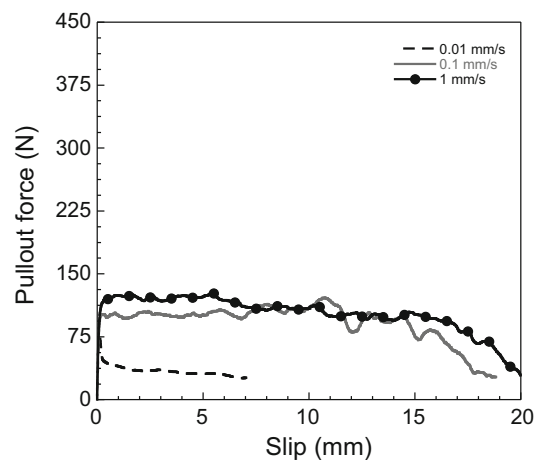

(a) Smooth fibers, angle $0^{\circ}$

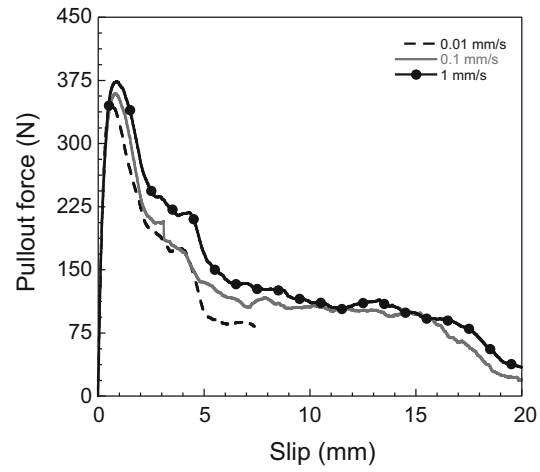

(d) Hooked-end fibers, angle $0^{\circ}$

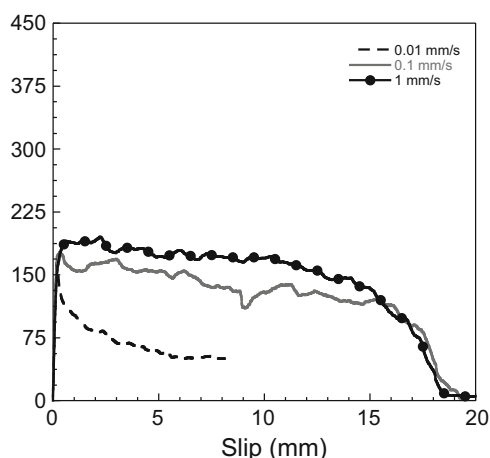

(b) Smooth fibers, angle $30^{\circ}$

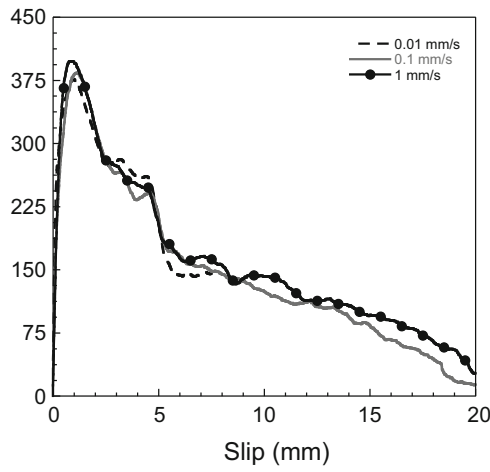

(e) Hooked-end fibers, angle $30^{\circ}$

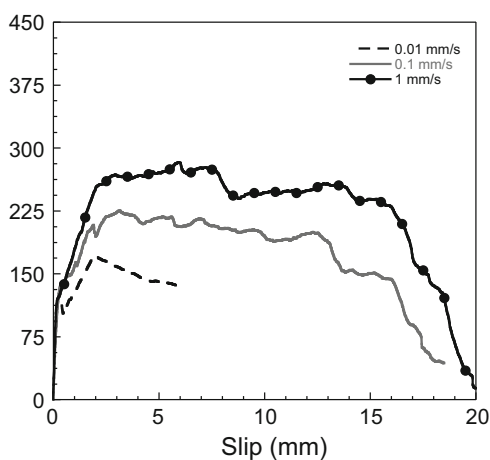

(c) Smooth fibers, angle $60^{\circ}$

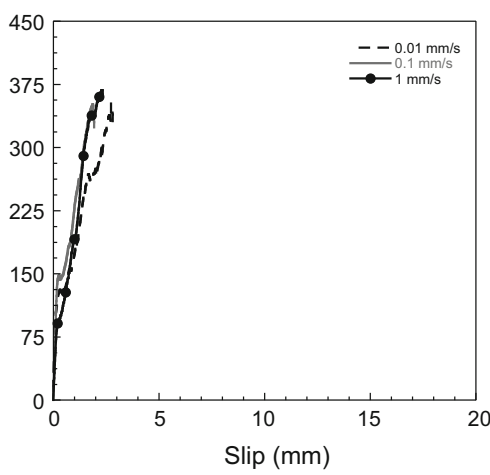

(f) Hooked-end fibers, angle $60^{\circ}$

Fig. 10 Average curves for smooth and hooked-end fibers by displacement pullout rate 


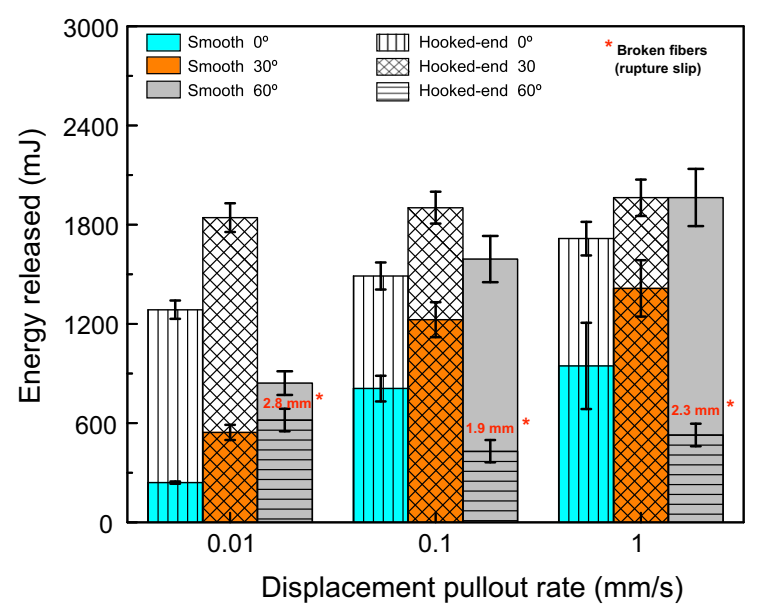

Fig. 11 Energy released in the pullout tests until a fiber slip of $8 \mathrm{~mm}$, in $\mathrm{mJ}$

fibers inclined at $30^{\circ}$, the energy grew the insignificant amount of $3 \%$ at a rate of $0.1 \mathrm{~mm} / \mathrm{s}$, and $6 \%$ at a rate of $1 \mathrm{~mm} / \mathrm{s}$. Finally, in the case of hooked-end fibers inclined at $60^{\circ}$ the comparison is not possible due to the fact that, as already explained, all the fibers ruptured before extraction.

The influence of the displacement pullout rate on the smooth fibers is clear and similar for the three inclination angles. In this regard, color filled columns in Fig. 11 show an almost equally increasing trend. On the other hand, the plot filled columns, representing the hooked-end fibers, remain at the same level showing its lack of sensitivity to the displacement pullout rate. The columns with horizontal plots represent the energy absorption by the hooked-end fibers inclined at $60^{\circ}$, and the slip at which the fibers have tensile ruptured (in average terms). Furthermore, the analysis of the displacement rate effect confirms that it has a greater effect on the total energy absorption than in the peak load.

The rate dependency of the smooth fibers is caused by its bond with the concrete. This bond is provided by the physicochemical mechanism, i.e. adhesion and frictional forces. In turn, the adhesion depends on the properties of the interfacial transition zone, ITZ, whose viscous-elastic/plastic nature makes it rate sensitive. Thus, the increase of the displacement rates results in higher performances in terms of fiber energy absorbed. Therefore, this research evidences that the use of smooth fibers in the reinforcement of concrete improves the energy absorption capacity of the mate- rial, and provides the FRC with great ductility. This concrete could be prescribed for high performance structures subjected to seismic or even impact loads.

However, the behavior of the hooked-end fibers with respect to the displacement rate is completely different. The anchorage provided by the hook of the hookedend fibers dominates over the physicochemical bond. The existence of a stiff hook causes the viscous elastic/plastic response of the concrete to not develop fully, whereby the hooked-end fibers are not influenced by the displacement rate.

\section{Conclusions}

In this research, 56 single pullout tests were performed on steel fibers. The experimental campaign focused on the investigation of distinct variables, such as the displacement pullout rates, ranging from quasi-static to dynamic, the type of fibers, smooth and hooked-end fibers, and the inclination angle, ranging from aligned fibers, $0^{\circ}$, to inclined fibers at $30^{\circ}$ and $60^{\circ}$.

From the experimental study, regarding the slip-rate effect, the following conclusions can be highlighted:

- The displacement pullout rate of the tests affected mainly the behavior of the smooth fibers. The comparison was performed in terms of peak load first and energy absorption later. The analysis confirms that the displacement pullout rate has a greater effect on the total energy absorption than in the peak load. Therefore, the increase of the energy absorption due to the displacement pullout rate in aligned smooth fibers reached almost $300 \%$, from the quasistatic rate to the dynamic one of $1 \mathrm{~mm} / \mathrm{s}$. These increments were reduced as the inclination angles of the fiber increased, i.e. $133 \%$ was observed for fibers inclined at $60^{\circ}$.

- The rate dependency of the smooth fibers is caused by the viscous-elastic/plastic nature of the interfacial transition zone of the bond. This behavior provides ductility to the smooth fiber reinforced concrete and makes it suitable to applications such as high performance structures subjected to seismic or impact loads.

- On the other hand, the energy absorption on the hooked-end fibers, taking the same displacement pullout rate range as a reference, varied from $33 \%$ in aligned fibers to only $6 \%$ in fibers inclined at $60^{\circ}$. This behavior is caused by the prevalence of the 
anchorage provided by the hook over the physicochemical bond. It makes the viscous-elastic/plastic response of the concrete not completely develop, and consequently the hooked end fibers are not sensitive to the displacement rate.

Furthermore, some other general conclusions can be pointed out:

- The type of fiber determined a completely different pullout behavior. Therefore, the resistance of the smooth fibers is defined by a physicochemical bond, i.e. adhesion and frictional forces. On the other hand, the mobilization of the mechanical anchorage of the hooked-end fibers significantly increased the peak load up to $250 \%$ in average terms with respect to the smooth fibers. This growth occurred for aligned fibers, while a smaller increase of $115 \%$ for fibers inclined at $30^{\circ}$ was observed, although some of them have tensile ruptured before being extracted. All the hooked-end fibers inclined at $60^{\circ}$ have ruptured before fully pulled out.

- The smooth fibers turned out to be more sensitive to the inclination angle than the hooked-end fibers. Thus, the series of smooth fibers experimented an enhancement in the peak load of up to $117 \%$, while in the hooked-end series the increment was negligible, of only $10 \%$. It should be noted that the slip at the peak load grew with the inclination angle, because of the increasing spalling of the matrix. Furthermore, some of the hooked-end fibers have ruptured before being extracted for an inclination angle of $30^{\circ}$, while all of them have ruptured for an inclination angle of $60^{\circ}$.

- The inclination angle produced spalling of the concrete matrix at the exit point of the fibers. The spalling was zero for aligned fibers and increased with the angle. Interestingly, the spalling produced by the smooth and hooked-end fibers for the same angle was similar to the naked eye.

The authors are planning to execute another experimental program for assessing the influence of concrete strength class and fiber embedment length on the behavior of fiber pullout under different displacement rates.

Acknowledgements The two first authors acknowledge the Financial support from Ministerio de Ciencia, Innovación y Universidades, Spain, through the project BIA2015-68678-C2-1-R. M. Tarifa appreciates the financial support from the Department of Applied Mechanics and Project Engineering, UCLM
(2018), and from the Programa propio de $I+D+i$ de la Universidad Politécnica de Madrid para realizar estancias de investigación internacional igual o superior a un mes (2019), to do two stays at the University of Minho, Guimarães, Portugal. E. Poveda acknowledges the funding from the International Campus of Excellence CYTEMA and the University of Castilla-La Mancha, throughout Ayudas para estancias en universidades y centros de investigación en el extranjero en 2019 en el ámbito del plan propio de investigación susceptibles de cofinanciación por el Fondo Europeo de Desarrollo Regional (FEDER), Programa 010100021 to fund her stays in the University of Minho during 2018 and 2019, respectively. The authors thank the support of the Department of Civil Engineering and the Laboratory of the Structural Division (LEST), University of Minho. The last two authors would also to acknowledge the support provided by the project ICoSyTec (POCI-01-0145-FEDER-027990) financed by FCT and co-funded by FEDER through the Operational Competitiveness and Internationalization Programme (POCI). We also appreciate the supply of fibers by the company Bekaert.

\section{References}

EN 12350-8 BE (2010) Testing fresh concrete. Self-compacting concrete. Slump-flow test, BSI

Abdallah S, Fan M, Zhou X (2016) Effect of hooked-end steel fibres geometry on pull-out behaviour of ultra-high performance concrete. Int J Civil Environ Eng 10(12):6

Abdallah S, Fan M, Zhou X (2017) Pull-out behaviour of hooked end steel fibres embedded in ultra-high performance mortar with various w/b ratios. Int J Concr Struct Mater 11(2):301313. https://doi.org/10.1007/s40069-017-0193-8

Abrishambaf A, Barros JAO, Cunha VMCF, Frazão C (2017) Time dependent behaviour of fibre pull-out in selfcompacting concrete. Cem Concr Compos 77:14-28. https://doi.org/10.1016/j.cemconcomp.2016.12.004

Abu-Lebdeh T, Hamoush S, Zornig B (2010) Rate effect on pullout behavior of steel fibers embedded in very-high strength concrete. Am J Eng Appl Sci 2:125-137. https://doi.org/10. 3844/ajeassp.2010.454.463

Alwan JM, Naaman AE, Guerrero P (1999) Effect of mechanical clamping on the pull-out response of hooked steel fibers embedded in cementitious matrices. Concr Sci Eng 1:1525

Banthia N, Trottier JF (1991) Deformed steel fiber-cementitious matrix bond under impact. Cem Concr Res 1:158-168. https://doi.org/10.1016/0008-8846(91)90042-G

Banthia N, Trottier JF (1994) Concrete reinforced with deformed steel fibers, part I: bond-slip mechanisms. ACI Mater J 91(5):435-446

Baran E, Akis T, Yesilmen S (2012) Pull-out behavior of prestressing strands in steel fiber reinforced concrete. Constr Build Mater 28(1):362-371. https://doi.org/10.1016/j. conbuildmat.2011.08.040

Bhutta A, Farooq M, Borges PHR, Banthia N (2018) Influence of fiber inclination angle on bond-slip behavior of different alkali-activated composites under dynamic and quasi-static loadings. Cem Concr Res 107:236-246. https://doi.org/10. 1016/j.cemconres.2018.02.026 
Bindiganavile V, Banthia N (2005) Impact response of the fibermatrix bond in concrete. Can J Civil Eng 32(5):924-933. https://doi.org/10.1139/105-039

Cunha VMCF, Barros JAO, Sena-Cruz JM (2008) Bond-slip mechanisms of hooked-end steel fibers in self-compacting concrete, Materials Science Forum. Trans Tech Publ. https://doi.org/10.4028/www.scientific.net/MSF.587-588. 877

Cunha VMCF, Barros JAO, Sena-Cruz JM (2010) Pullout behaviour of steel fibres in self compacting concrete. ASCE J Mater Civil Constr 22:1-9

Gokoz UN, Naaman AE (1981) Effect of strain-rate on the pull-out behaviour of fibres in mortar. Int $\mathrm{J}$ Cem Compos Lightweight Concr 3:187-202. https://doi.org/10.1016/ 0262-5075(81)90051-8

Kim DJ (2009) Strain rate effect on high performance fiber reinforced cementitious composites using slip hardening high strength deformed steel fibers. Ph.D. thesis, The University of Michigan, Michigan, USA

Kim DJ, El-Tawil S, Naaman AE (2008) Loading rate effect on pullout behavior of deformed steel fibers. Concr Sci Eng 6:576-584

Kim DJ, El-Tawil S, Naaman AE (2009) Rate-dependent tensile behavior of high performance fiber reinforced cementitious composites. Mater Struct 42(3):399-414. https://doi. org/10.1617/s11527-008-9390-x

Laranjeira F (2010) Designed-oriented constitutive model for steel fiber reinforced concrete. Ph.D. thesis, Universitat Politècnica de Catalunya, Barcelona, Spain

Laranjeira F, Aguado A, Molins C (2010a) Predicting the pullout response of inclined straight steel fibers. Mater Struct 43(6):875-895. https://doi.org/10.1617/ s11527-009-9553-4

Laranjeira F, Molins C, Aguado A (2010b) Predicting the pullout response of inclined hooked steel fibers. Cem Concr Res 40(10):1471-1487. https://doi.org/10.1016/j. cemconres.2010.05.005

Leung CKY, Ybanez N (1997) Pullout of inclined flexible fiber in cementitious composite. J Eng Mech 123(3):239-246. https://doi.org/10.1061/(ASCE)0733-9399(1997)123: $3(239)$

Markovic I (2006) High-performance hybrid-fibre concrete: Development and utilisation. Ph.D. thesis, Delft UnivERSITY of Technology, Delft, Netherlands

Naaman AE, Namur GG, Alwan JM, Najm HS (1991a) Fiber pullout and bond slip I: analytical study. J Struct Eng 117(9):2769-2790
Naaman AE, Namur GG, Alwan JM, Najm HS (1991b) Fiber pullout and bond slip. II: experimental validation. J Struct Eng 117(9):2791-2800. https://doi.org/10.1061/ (ASCE)0733-9445(1991)117:9(2791)

Nammur G, Naaman AE (1989) Bond stress model for fiber reinforced-concrete based on bond stress-slip relationship. ACI Mater J 86(1):45-57

Nieuwoudt PD, Boshoff WP (2017) Time-dependent pullout behaviour of hooked-end steel fibres in concrete. Cem Concr Compos 79:133-147. https://doi.org/10.1016/ j.cemconcomp.2017.02.006

Nonato Da Silva CA, Ciambella J, Barros JAO, Costa IG (2019) Analytical bond model for general type of reinforcements of finite embedment length in cracked cement based materials. Int J Solids Struct 167:36-47. https://doi.org/10.1016/ j.ijsolstr.2019.02.018

Pompo A, Stupak PR, Nicolais L, Marchese B (1996) Analysis of steel fibre pull-out from a cement matrix using video photography. Cem Concr Compos 18:3-8. https://doi.org/ 10.1016/0958-9465(95)00034-8

Poveda E, Yu RC, Tarifa M, Ruiz G, Cunha VMCF, Barros JAO (2019) Rate effect in inclined fibres pull-out for smooth and hooked-end fibres: a numerical study. International Journal of Fracture. https://doi.org/10.1007/s10704-019-00404-7

Robins P, Austin S, Jones P (2002) Pull-out behaviour of hooked steel fibres. Mater Struct 35(251):434-442. https://doi.org/ 10.1007/BF02483148

Tai YS, El-Tawil S (2017) High loading-rate pullout behavior of inclined deformed steel fibers embedded in ultra-high performance concrete. Constr Build Mater 148:204-218. https://doi.org/10.1016/j.conbuildmat.2017.05.018

Tai YS, El-Tawil S, Chung TH (2016) Performance of deformed steel fibers embedded in ultra-high performance concrete subjected to various pullout rates. Cem Concr Res 89:1-13. https://doi.org/10.1016/j.cemconres.2016.07.013

Xu M, Hallinan B, Wille K (2016) Effect of loading rates on pullout behavior of high strength steel fibers embedded in ultrahigh performance concrete. Cem Concr Compos 70:98109. https://doi.org/10.1016/j.cemconcomp.2016.03.014

Publisher's Note Springer Nature remains neutral with regard to jurisdictional claims in published maps and institutional affiliations. 